\title{
Digital content unleashed
}

\author{
Michael Wolf \\ worked at In-Stat, prior to joining ABI, where he pioneered the company's home networking and digital consumer media and \\ content research. He has also served as the Director of Consumer Digital Imaging at InfoTrends, and in strategic planning for \\ Avnet, a Fortune 500 semiconductor distributor. He has been quoted in such publications as The New York Times, Time Magazine, \\ The Wall Street Journal and Business Week about consumer technology trends, and has served as commentator for such outlets \\ as MSNBC to discuss the communications technology market. He has been a columnist for Network World and has published a \\ book on home networking technology. He is a graduate of Seattle Pacific University and received an MBA from Thunderbird, the \\ Garvin School of International Management.
}

\section{Clint Wheelock}

was Vice President, Wireless, at the NPD Group, prior to joining ABI Research, where he established and expanded the company's wireless research practice focused on mobile devices, multimedia content and voice and data services. He also served as Director of Wireless Research at In-Stat, where he managed analyst coverage of worldwide wireless technology and end-user markets. His previous industry experience includes senior product management, new product development and marketing strategy positions focused on mobile wireless, broadband and consumer video services at Qwest Communications and Verizon Communications (then GTE).

Keywords: media management, digital media, storage, content management, online content, consumers

Abstract The world in which consumers use a variety of isolated devices to enjoy prepackaged entertainment delivered over isolated networks and legacy retail channels is beginning to fade away. In the world that is emerging, consumers are empowered to choose the way they purchase, use and manage their media. Increasingly, they are taking advantage of these opportunities. While the convergence of different networks, the enabling of networked and broadband consumer electronics devices and the vast array of content available to buyers are all creating a new generation of empowered consumers, however, $A B I$ Research finds that many are having a difficult time accessing and managing this content in any cohesive way. Some major players have worked to create solutions to help consumers access and manage the wide variety of content at their disposal through tightly integrated hardware, software and service packages. The best example is Apple with its $\mathrm{iPod} / \mathrm{iTunes}$ pairing. While the iPod/iTunes ecosystem is perhaps the closest thing to an organized approach to digital media, as more users look to connect to content anywhere at anytime, they will find technology barriers, old frameworks and business interests of incumbents' appearing to prevent this. These barriers essentially create friction in the entertainment experience, slowing the consumer's anytime-anywhere experience and possibly preventing it all together. This white paper examines consumer behavior today in terms of pay media, online content, digital media storage and management. We will look at how new enabling technologies will drive adoption of new use-cases among an increasingly large number of users, and how this will create a need for more centralized management of their digital media. Finally, we make some predictions for 2012 and assess the possibilities of achieving a friction-free media world that will ultimately benefit consumers, content creators, distributors and end-user system manufacturers. Journal of Digital Asset Management (2007) 3, 247-258. doi:10.1057/palgrave.dam.3650093

Michael Wolf PO Box 452, 69 Hamilton Avenue, Oyster Bay, NY 11771 USA Tel: +1516 6242500 Fax: +15166242501 E-mail: wolf@abiresearch. com

\section{DIGITAL CONTENT UNLEASHED}

\section{The slow but inevitable race toward a friction-free media world \\ Much of this white paper is based on a survey of approximately 1,192 online}

households in the United States completed in 2Q 2007. The survey covered a number of different age groups, as shown in Figure 1 and across a variety of different income groups, illustrated in Figure 2. 


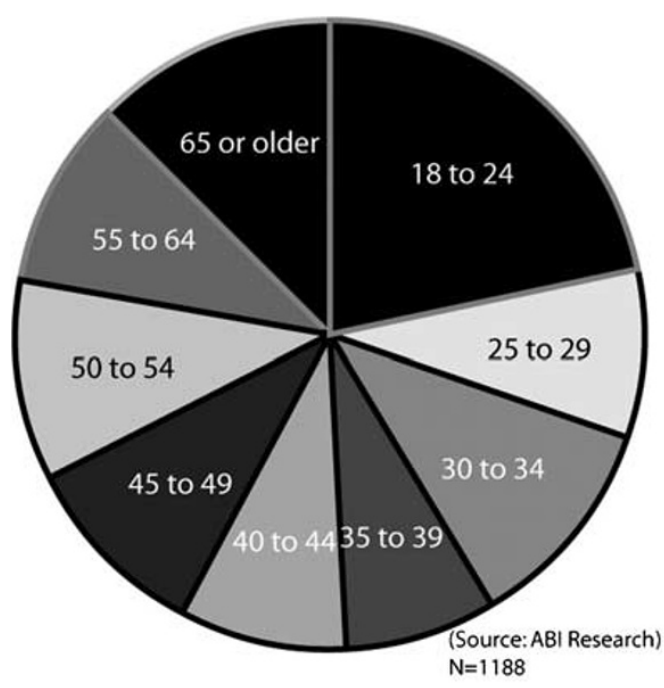

Figure 1: Age of survey respondents

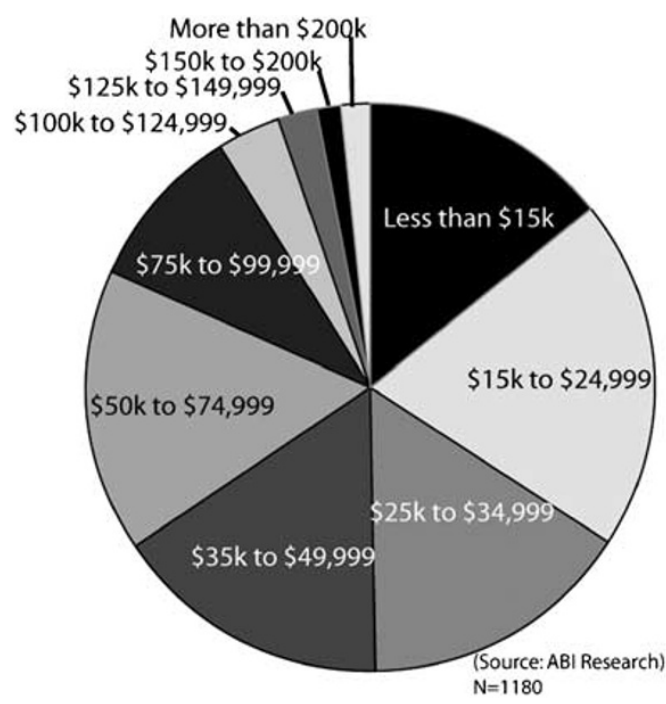

Figure 2: Incomes of respondents

\section{The consumer today}

As illustrated in Figure 3, certain devices can be considered universally appealing and accessible. Ownership of such devices is common enough that almost any consumer with even a low to moderate income can purchase such systems for their household. The personal computer, DVD players, printers, cellphones and digital cameras are considered extremely mature device categories. Each of their respective markets has expanded enough to create a wide array of products in different price ranges to satisfy most consumers.
Beyond these products, however, an array of devices has been adopted widely enough to be considered mainstream, but not to the point where ownership of such devices can be assumed for each household. Some of this is dependent on income, but it relates to the device itself, and whether consumers see value in the experience and applications delivered by such a product. The best example is a game console, which falls into the mature product category. Only a segment of the population is, however, actively interested in gaming as an application. While Sony, Microsoft and Nintendo see the expansion of the gaming demographic profile as key to their future growth, by and large, owners of such consoles are those who take an active interest in gaming.

\section{Do new options create new use cases and drive demand for new products?}

Whether adoption of emerging device groups (as well as more mature categories such as game consoles) can be accelerated by the integration of new connections and ways to push content onto these devices remains a question. ABI Research believes that there is a strong tie between the adoption of a device by a large consumer base and the maturity of the distribution networks. This is exemplified by mobile video, an application that, while growing, has not been adopted widely. This is due in part to the fact that, while mobile phones are one of the most widely accepted technology devices, mobile broadband and mobile broadcast networks are fairly new. The cost is still high and the overall experience among consumers for the first generation of services may have been only moderately satisfying (Figure 4).

But the answer goes beyond whether a distribution network has been built out. Other devices that enable new use-case scenarios have not been widely adopted, due in large part to the fact that many consumers are still unclear about their value. Some, like media adapters and home servers, bring new ways to manage content. They are, however, primarily still used only by digital enthusiasts willing to purchase new systems, even when the overall complexity may be high and the benefits not entirely proven. In many cases, these early adopters are willing to put up with initial generations of 


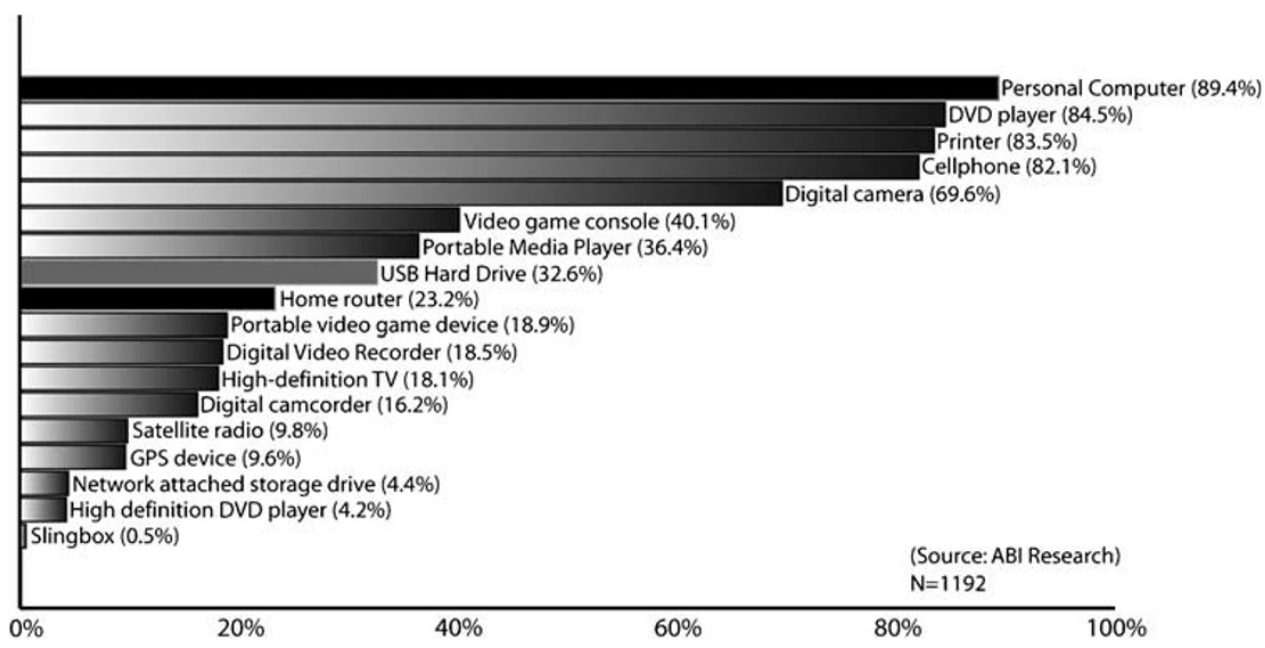

Figure 3: Which of the following consumer electronics devices do you currently own?

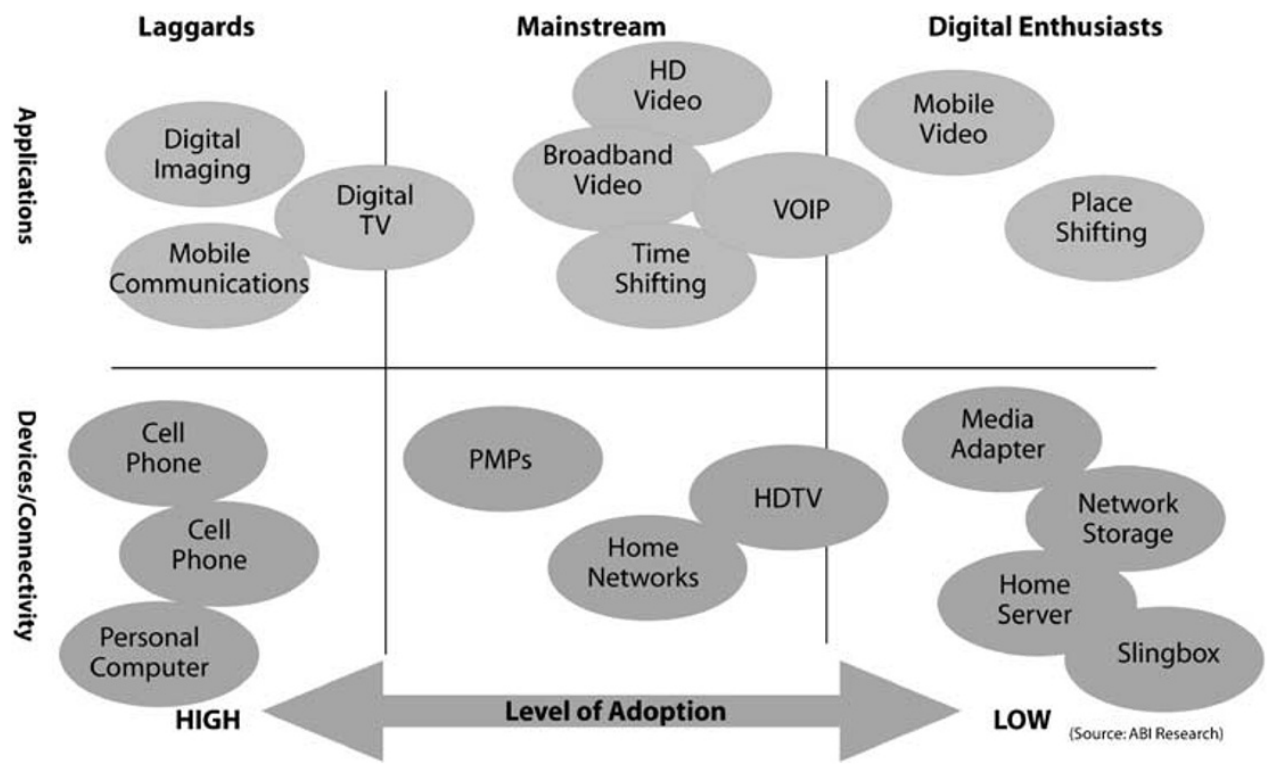

Figure 4: Device and applications adoption continuum

products that may place a higher burden on the end user from a technical perspective because these early adopters can understand the promise of these devices. In other words, they forgive the shortcomings for the promise of what these devices ultimately deliver in end-user benefits.

Certain device classes such as media adapters may not be widely adopted at all. This is not because a connected client cannot deliver significant end-user benefits, but because one particular instance of a product (media adapter) may lose out to another (embedded media client in a more traditional CE device category) and because the winner delivers more value to the consumer (a specific and well-recognized application such as video games and networked client).

In addition (and perhaps most important), the experiences delivered by the devices on the far right of the graphic have not succeeded to date because the user experience has not been well tuned for a mass market. The inaccessible nature 
of user benefits by a wide audience — or lack of a "friction-free" experience — is due to such factors as a difficult set up, lack of content, lack of interoperability and so on. These hurdles need to be eliminated or reduced substantially before such devices move toward the center and, ultimately, the left of Figure 1.

Ultimately, some of the devices on the far right of the graphic will see widespread adoption, but it will take time. Our survey shows that only a small percentage of consumers are using devices such as network-attached storage and Slingboxes. We believe that the benefits that these devices offer will spur more widespread adoption.

To assess how far we have to go to such a world, there is a need to look at the position of consumers relative to adoption of new media formats and services and management/storage of this media.

\section{New ways to consume media versus traditional methods: growing use of new media}

Our survey of consumers in the United States indicates that nearly 50 per cent are watching some form of video on their PCs (Figure 5). It may come as a surprise that video content delivered through a browser outranks that of
DVDs as the most popular form of video. According to the survey, 72 per cent watch some form of video through their browsers, while nearly 65 per cent of these same respondents watch DVDs on their PCs. Perhaps not so surprising is that 7.1 per cent are watching pay television delivered over carrier networks on their PCs. This is perhaps a sign that, while some efforts such as Microsoft's Media Center PC have seen wider adoption over the past few years, those who are actually using a television tuner to watch and record television on these PCs is still fairly low (Figure 6).

While only a small percentage of consumers may be watching pay television on their PCs, pay television does play a significant part in most consumers' overall video entertainment viewing. In fact, 95 per cent of those surveyed indicated that they use some form of pay or broadcast television service and, of them, the large majority use cable or satellite. While some may believe that terrestrial broadcast is a thing of the past, our survey showed that a significant percentage of respondents -13.6 per cent use terrestrial as their primary television service (Figure 7).

Given the continued high use of pay television services, it is easy to assume that consumers are still within a legacy framework

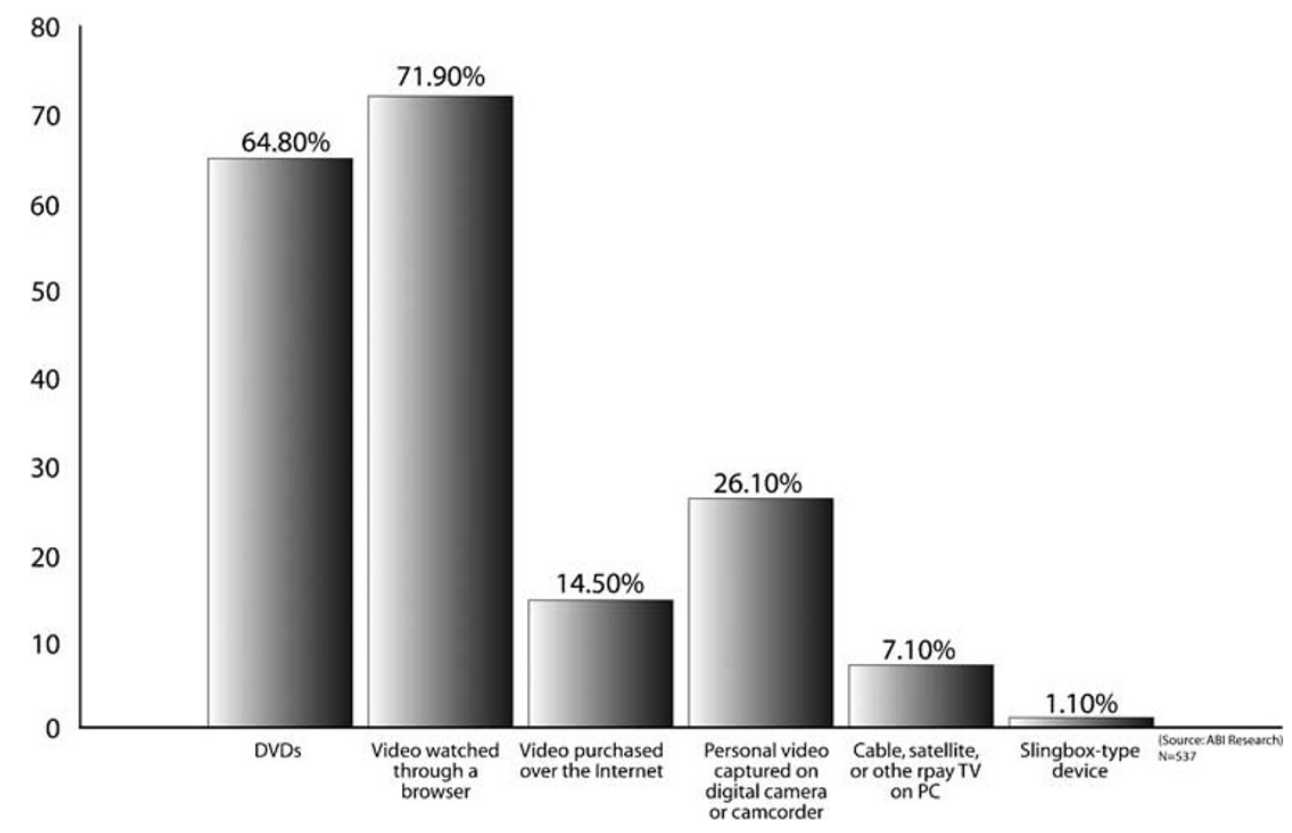

Figure 5: Which of the following describe(s) the way(s) you watch video on your PC? 


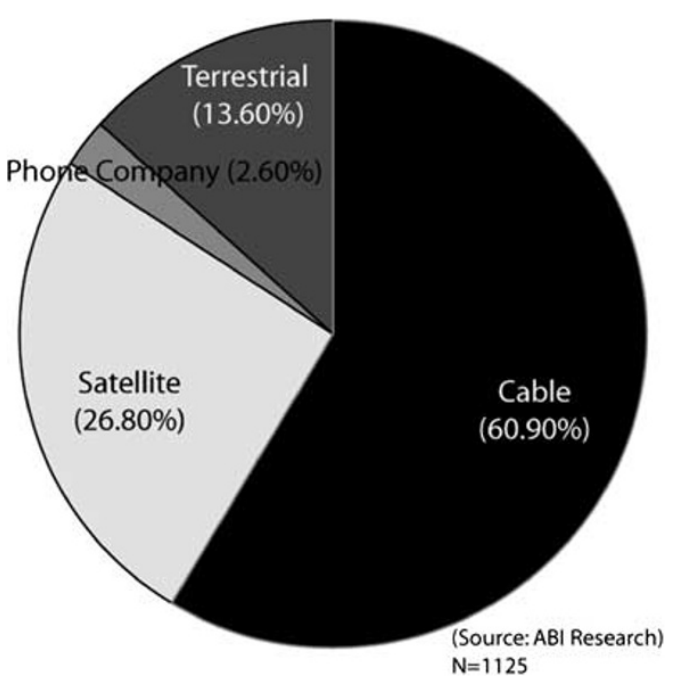

Figure 6: Type of pay television service

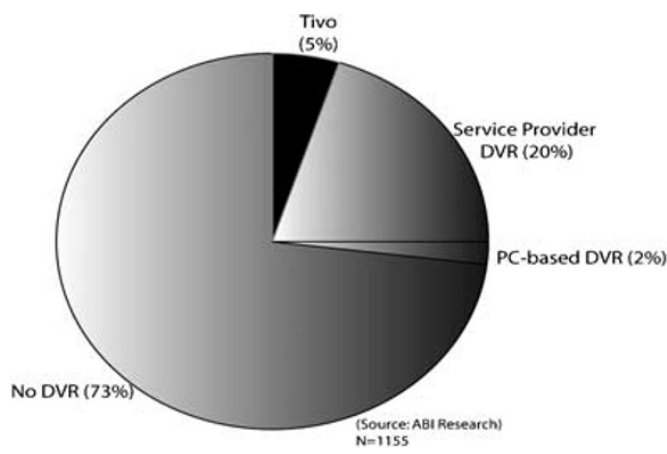

Figure 7: Do you use a DVR?

for watching television in linear format and not taking more control of their media. This assumption proves false, however, as can be seen by the fact that over one-quarter of those surveyed are using some form of DVR. While many use TiVo, the dominant name in nonservice provider DVRs, our research shows that a solid majority of those use set-top box DVRs supplied by their pay television providers. This high penetration of service provider DVRs shows that a significant number of consumers, while still getting a substantial amount of their entertainment through traditional closednetwork delivery, are increasingly taking advantage of disruptive technologies such as time-shifting, even if they are in packages sold by traditional providers of entertainment services (Figure 8).
We asked our survey respondents about a variety of ways in which they acquire media, comparing traditional methods such as cable service, VOD and DVDs with newer methods. While it is not surprising that the dominant methods include through service providers and optical disk formats, it is interesting to note the growth in newer methods such as online video purchases. While only 12 per cent of our respondents bought online video, the increase since late 2006 has been impressive. According to our survey, in October 2006, less than 5 per cent of respondents had purchased video content online, compared with 12 per cent of respondents in the second quarter of 2007. This is also striking when compared with the number of consumers who purchased music tracks online -13 per cent of respondents. The online music market is much more mature than that of online video, and the fact that nearly as many respondents purchased online video as well as online music speaks to the viability of this market.

\section{Consumer media management today}

One of the important aspects of digital media is how consumers store and manage their content. ABI Research believes that, over time, more consumers will store their digital media in centralized locations, while also maintaining certain "satellite" settings for digital media, often where the content is used for playback. These satellite locations are not difficult to define: digital music is and will continue to be stored on consumers' portable media players; digital video will increasingly be stored on video playback devices near televisions; and so on (Figure 9).

Certainly, one of these central locations will be a PC, since that is where most consumers store digital media content today. While most users will not look to non-PC devices as their primary storage locations for digital media in the next year or so, over time, however, non-PC systems will become increasingly "in-play" as centralized storage devices. Whether this means a PC-like home server (including Microsoft's new Windows Home Server), a NAS device or a true consumer electronics system, consumers are looking for ways to diversify beyond simply storing all of their content on their main PC hard drives. 


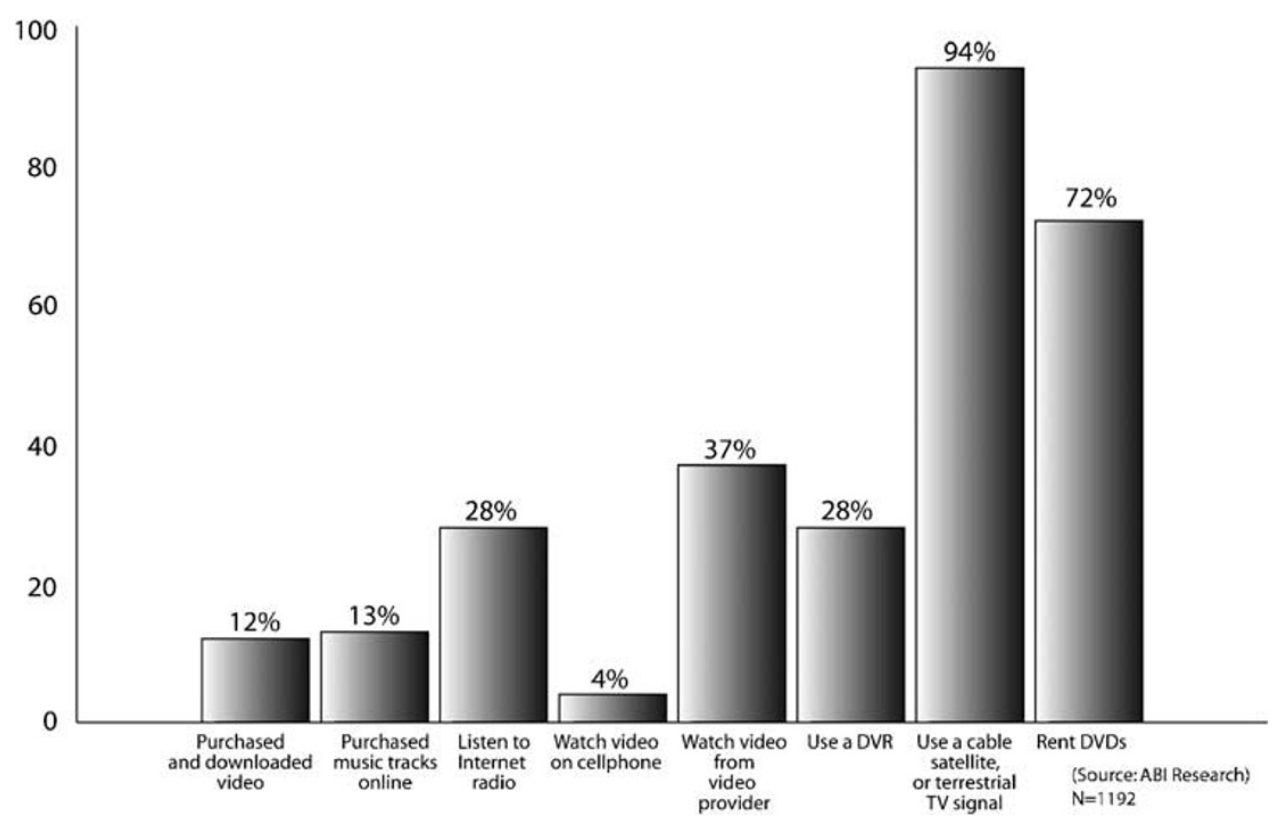

Figure 8: Media consumption by type: new versus old

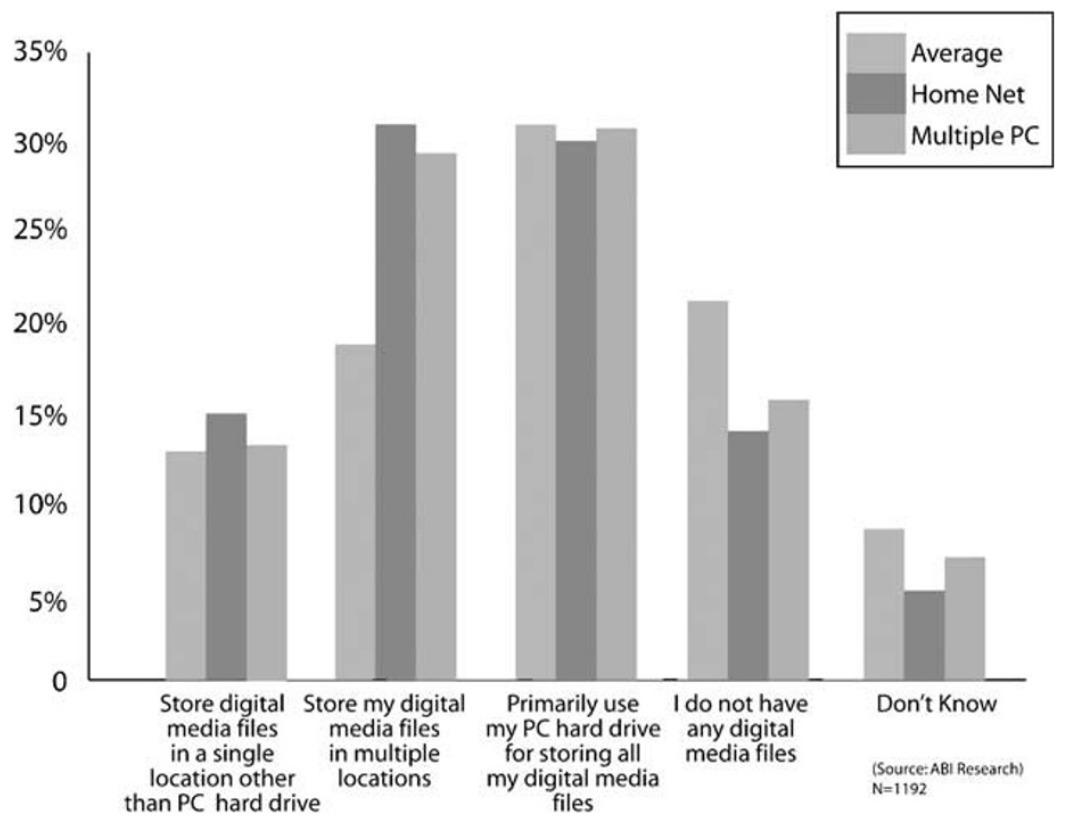

Figure 9: Do you have a storage location (USB hard drive, CD, DVD, online storage), other than your PC hard drive, where you store your digital media files? Digital media includes electronic files such as MP3 and other digital music files, digital photos and videos

Our question of whether consumers store their content in locations other than their PC hard drives showed some intriguing results. When asked whether they stored their digital media in centralized locations other than their
PCs, the results differed somewhat between the average respondent versus those who had home networks. While 22 per cent of respondents overall used multiple locations to store content, those with home networks were one-third more 
likely to store their digital media in locations other than just a single PC hard drive. This indicates that the home network is a driver not only to view content on different devices but also to diversify the storage of content among different devices. It should be noted, however, that, while home network users are more likely to use locations other than a single PC hard drive, those home network owners were nearly as likely as the average user to say that the PC is their primary storage location for digital media (Figure 10)

Another interesting (and potentially discouraging result for those interested in network storage) was the response of consumers regarding their primary non-PC storage ocation for digital media. The most common location was CDs - nearly 63 per cent of those who said they used alternative storage means. This compares with nearly 57 per cent who used USB hard drives. The prevalence of CDs (and DVDs at 30 per cent) shows that we are still very much in a "SneakerNet" world, despite the growth of home networks and network-acquired digital media such as online video. Consumer habits are difficult to alter, and for most, the CD is the modern equivalent of the audio cassette and the VHS tape, mediums with which they can easily record and store content for playback on a variety of different devices. Only 8 per cent of those who said they use alternative storage locations indicated they use NAS (Network Attached Storage), a number that was smaller than online backup or online e-mail services such as Yahoo or Gmail.

\section{Demand for cohesive, friction-free media management will increase, but why?}

As indicated by the survey results, while consumers are increasingly looking at new ways to acquire digital media outside of traditional delivery formats, their management and storage behavior is rooted in the legacy behaviors developed over decades, despite any inclinations to change within the acquisition of new media. These are not just long-acquired habits (although that is a large part of it), but also due to the fact that these behaviors are consistently reinforced by market realities such as lower prices for legacy storage formats as well as the continued propagation of these methods by current applications.

Hence, if consumers are using what is familiar, easiest for them and the most affordable way of managing and storing content, why make the case for more unified and centralized management of content?

\section{Incorporation of new technologies will increasingly enable friction- free centralized media access and management}

Over time, we expect that access to content anywhere at anytime in the home will become more "friction-free." Today, many impediments create what is essentially a high degree of friction when accessing content over both local and wide area networks. DRM, different wide area and local area networks, a variety of media formats and codecs all add to confusion and frustration on the part of the consumer. Many

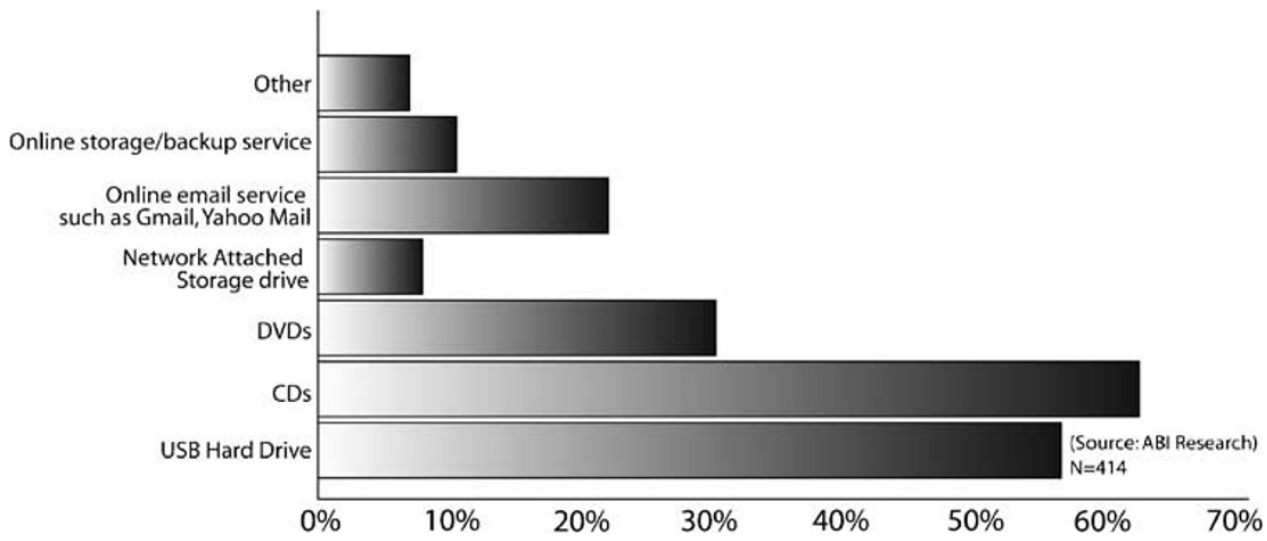

Figure 10: What is your primary device(s) for storing your digital media (other than your PC hard drive)? (Select all that apply) 
of these impediments, however, will lessen as technologies that allow content to traverse different networks and formats solidify. Whether it is through transcoding of content for the appropriate media format, the adoption of "universal" DRM technology (or the elimination of DRM altogether), as well the increasing use of discovery layers such as UPnP or Bonjour, these developments will help eliminate friction in connecting and receiving content (Figure 11).

\section{Increased choice of content will drive demand for systems that enable greatest amount of access}

As consumers learn how to break down the traditional usage paradigms for content, they will increasingly want the freedom of anywhereanytime access. Additionally, the continued proliferation in the variety of new forms of content available through network-based delivery will fuel growth for this content and associated hardware for playback and management. Essentially, increased choice for consumers will beget demand for more choice, enabled by the accelerating effect of the technologies that lower barriers to these new ways of managing content. In summary, increased choice of content will ultimately provide added opportunity for the monetization of products by platform makers, content owners and service providers (Figure 12).

\section{The slow move toward friction-free media: some predictions for $\mathbf{2 0 1 2}$}

Friction-free access to content anytime and anywhere will ultimately become a reality for many consumers, but it will be a slow move rather than a fast one. How quickly will this happen? The following are a few predictions for the coming five years.

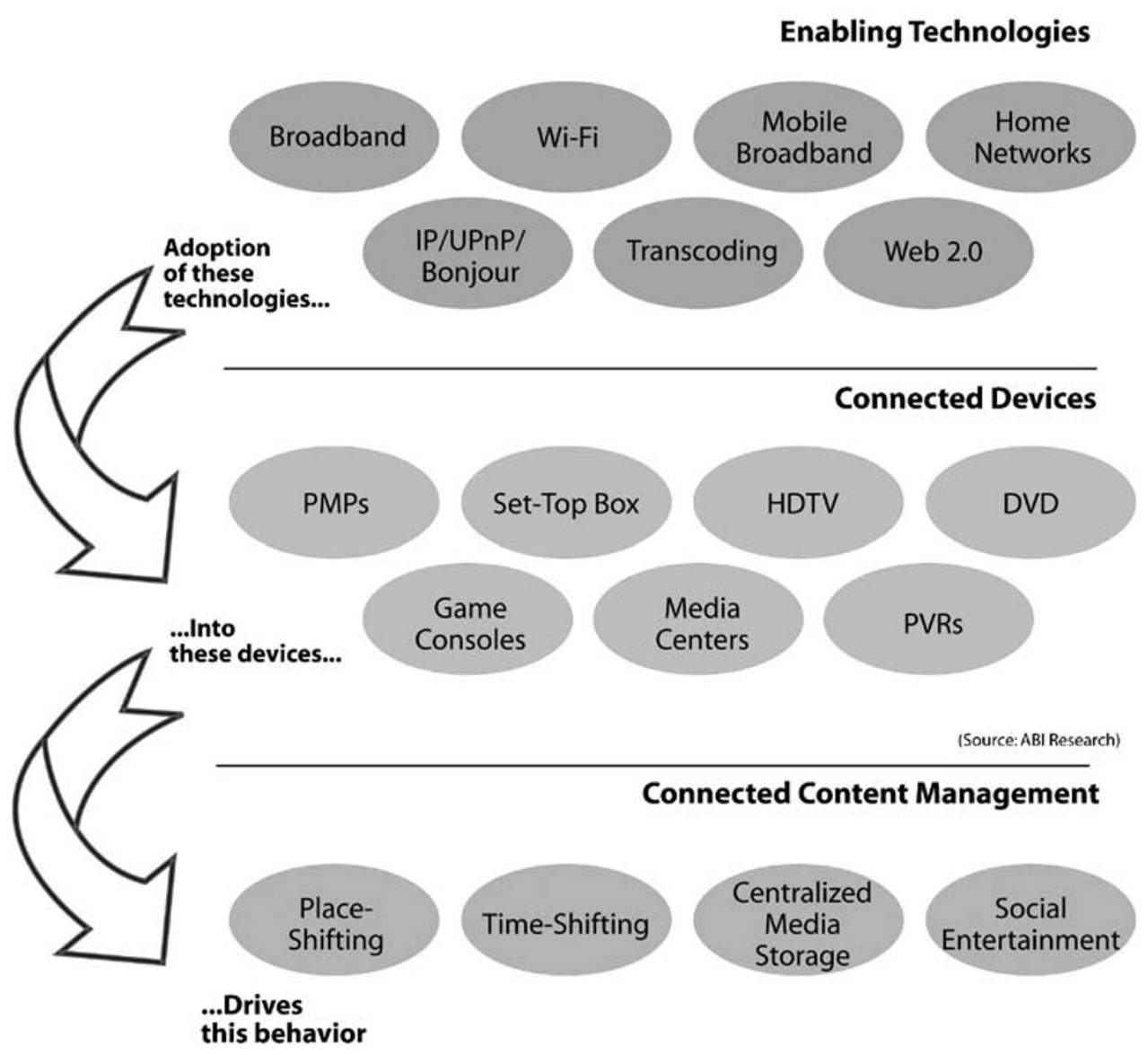

Figure 11: Enabling technologies in connected devices encourages new ways to manage content 


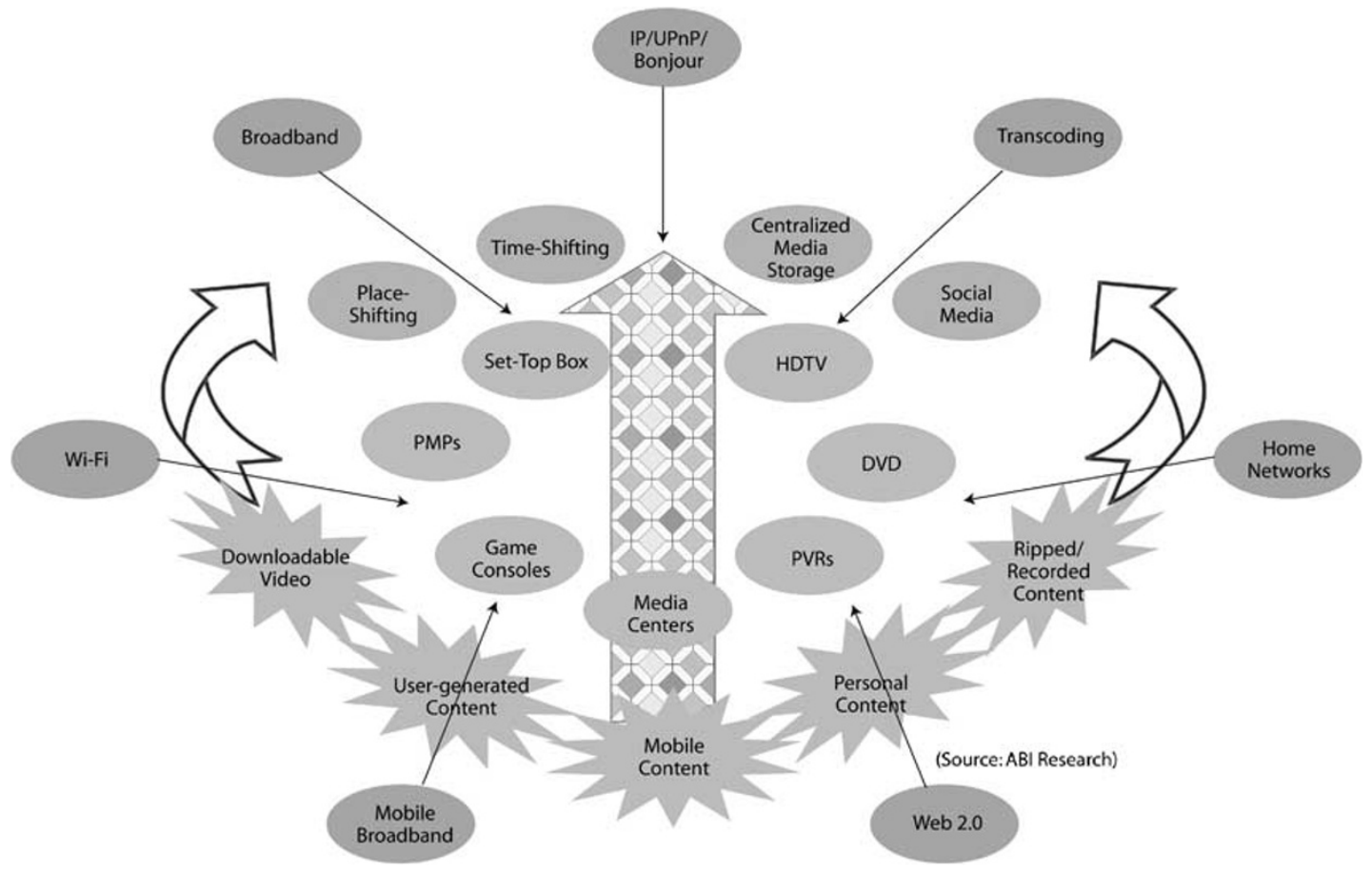

Figure 12: Increased content enabled by connected devices creates use of new media management techniques

\section{Wide area and local networking will be standard on most consumer electronics devices}

Today, most forward-thinking consumer electronics companies are looking at how they can best incorporate both local and wide area networking into their devices. Already, we have heard that at least one of the next generations of handheld gaming consoles will have $3 \mathrm{G}$ or $4 \mathrm{G}$ technology. Portable media player vendors such as Archos have indicated that they are considering technologies such as WiMax for future generations of these products. Factor in that an increasing number of mobile phones will begin to operate more like the iPhone (in functionality if not simplicity or user interface, where Apple excels beyond nearly every company today). This will result in the ability to access content in the cloud and, in some cases, stored on a consumer's own devices remotely.

\section{Key consumer electronics device categories will transform into network clients}

The media adapter as a category has been a disappointment. Despite the best efforts by large
IT companies such as Intel, Microsoft, Linksys, NETGEAR and Philips, devices such as media adapters without a clear purpose other than being a network client have not and will not succeed. These devices, from a packaging perspective, need to be a lion in sheep's clothing, serving as a television or DVD player, and keeping the power of the network as secondary.

\section{Fixed-mobile convergence for entertainment will become crucial}

One of the most important factors in creating friction-free media will be the ability to connect the fixed and mobile worlds. Set-top boxes, TiVos, PCs and other devices will be large reservoirs of content for consumers and increasingly that content will be unleashed through enabling technologies for time- and place-shifting. The most prevalent pocket device for consumers will continue to be the mobile phone. Connecting these devices over the local or the cellular network will be important for transfer of content as well as content management. Side-loading, network streaming and scheduling of content will all be important features of fixed-mobile convergence for 
personal entertainment. "In-the-cloud" media conversions that enable internet-to-mobile format transcoding from companies such as Bytemobile will also help to create a more friction-free media experience between the online and mobile worlds.

\section{The simultaneous breakdown and growth of the walled garden}

Over the next five years, we will witness both the breakdown and the growth of the walled content gardens. Traditional walled gardens in the pay television and mobile space are becoming more porous as new forms of connectivity and bountiful content offerings on the open internet are increasingly enticing the consumer toward new horizons. At the same time, major players such as Google are pushing for open access for their applications on mobile networks, and many traditional pay video providers are looking at ways to increase choice beyond their conventional closed menus of options.

The traditional walled garden will see a breakdown as consumers push for more choice. We also believe that new media walled gardens that provide entire hardware-software-delivery network ecosystems such as iTunes/iPod/iPhone and those supplied by the large video game console providers will continue to attract buyers who want the easiest and most user-friendly way of accessing content. While this is slightly counter to our belief that the larger population will want to take advantage of the growing freedom of choice and mobility that a networked-based content world provides, we feel that this growth is only temporary and, in some ways, achievable by only a few select players. The more likely long-term solution for the mass market for widespread adoption of friction-free media will be ubiquitous software frameworks based on web standards packaged with hardware across a variety of networks tied to these software frameworks.

\section{DRM will still create friction, but it will lessen over time}

DRM is necessary or, at least, that is how most content providers see it. For video, the issue will not go away. Over time, however, the market will evolve to allow more universal DRM layers that will enable access to content with less friction, even if friction remains to the degree that specific closed ecosystems such as iTunes/ iPod/iPhone/Apple TV continue. Technologies such as DTCP-IP (a required component of DLNA), which enable network delivery of content with DRM to the home, however, will become more important, and this will result in an increasing number of solutions where deviceto-device transfer of content becomes possible. Another example of movement toward less friction in content protection schemes is the interoperability efforts across proprietary DRM schemes by the Coral Consortium. Others believe that the OMA 2 DRM scheme for mobile could also serve as a standard for DRM beyond just the mobile network. The availability of a large amount of content that either has no DRM, low-threshold DRM (DRM that is largely invisible to the consumer and prevents viewing in a very low percentage of cases) or DRM interoperability will ultimately win the market for most popular content and premium content such as movies. Sports content will move toward either de facto or outright standards.

\section{The lowering of walls between private and open delivery networks for video}

Today, the inclusion of IP backchannels is becoming more common in carrier set-top boxes. Devices such as the DirecTV HD20 HD DVR set-top box include Viiv technology for connecting to a PC, while others such as EchoStar's STBs include HomePlug LAN for connecting to the network. The explosion of IPTV in countries across Europe means that most of these boxes will have native IP connectivity for both closed and open internet delivery. These developments will accelerate as service providers respond to increased calls from consumers to allow them to access their own content acquired over the internet, as well as personal content such as digital photos and home video.

\section{Centralized storage moves from extreme early adopter to early mass market}

Centralized storage across all content in the home is available to only a few extreme early 
adopters today. There are some content-specific managed solutions such as 2-room PVRs that create some centralized content management for consumers, but these are only in early stages and are limited in scope. Those who use NAS devices or multi-content media servers number less than 5 per cent of the population today but, over time, this will grow significantly to include the initial mass market. Closed solutions such as managed set-top boxes as well as retail-based products with walled-garden or limited service offerings will be more common in the mass market. In addition, systems such as Windows Home Server will create early mass-market adoption of true PC servers, while Windows Media Center and Apple Front Row type of applications will increasingly push standard computing platforms as media servers.

\section{In-the-cloud storage by providers such as Google}

We believe that storage of a consumer's content will be a mixture of both in-the-cloud as well as centralized storage in the home. Google's vision is to enable the internet as the central storage medium for consumers' content. We believe the company wants to acquire or build all of the pieces to enable the most friction-free delivery of this content through the creation of software and presence on as many clients as possible who can then access this content in the cloud.

\section{Physical formats, SneakerNet and cable television are NOT going away}

Perhaps the most important prediction: while increased use of the network for media transport will continue and more consumers will want to centralize and have more cohesive management of content, today's dominant methods of delivery are not going away. DVDs will continue to be important, particularly for HD video as the network for the public internet would simply not be able to withstand a conversion of all those videos delivered in optical format to network-based delivery. Likewise, many consumers prefer actually owning physical copies of their media, as is the case with many of those who use internet VOD.

Pay television over closed networks will not see significant decreases in consumers looking to go completely "a la carte" using public internet delivery. However, we expect a certain segment of the population with narrow interests to do this when it is a viable option from an ease-ofuse standpoint. Quite simply, those who have an interest in a certain content that can be acquired through a nonservice provider network delivery option will do so if it makes economic sense. For some, it will. We believe, however, that service providers will continue to adapt their offerings and offer a mix of both closed network delivery of their most premium content as well as incorporate interactive applications and access to content where it makes sense from the public internet.

\section{Conclusion}

While we do expect that barriers will fall to allow for more friction-free access to media across a variety of devices, we believe that there are some ways in which device manufacturers, software makers, content owners and network operators can make this transition easier. Over time, enabling this transition will ultimately benefit these companies as much as it will assist consumers. This is true, in part, because - by resisting the migration toward friction-free media - these companies will ultimately create dissatisfaction among customers, resulting in a migration toward best-in-class products that allow fewer user headaches and more freedom.

We also feel that walled-garden content services will remain popular for a segment of consumers. Keeping users within their closed ecosystems will mean less friction in the media consumption experience. We believe, however, that only a select few vendors can do this on a large scale, and even those, such as Apple, who focus nearly exclusively on closed ecosystems, are seeing the benefit of opening doors to the internet for greater choice of content for consumers.

Part of the move toward friction-free media will help buyers find better ways to manage their content in a networked world. Seamless ties between the mobile, video and IP networks to move and manage content will be a major element of this. While legacy business models and legitimate concerns over piracy, consumer retention and preserving ultimate control over the consumer experience will, in some ways, limit the move by the different players in the 
ecosystem, those who enable consumers to more cohesively manage their content while offering the greatest choice of content will win in the long term.

\section{RELATED REPORTS}

Broadband video and Internet Television: Analysis of Pay and Ad-Supported Distribution Networks and Enabling Back-end Services for Broadband Video

The upsurge in the amount of quality video available on the public internet has created monumental shifts in attitudes over the past year about whether online video will be a viable and growing market for monetization of video assets. This shift has been most notable among large content owners such as television networks. It is also seen in providers of online video destination sites, as well as both back-end publishing, and syndication capabilities, and CDNs that are helping to enable these services as they provide necessary bandwidth, caching and video acceleration services. This study examines every aspect of the online video market from consumer adoption of Internet video (examining two broad-based consumer surveys taken in April 2007 and October 2006), the back-end enabling service providers in the BBV ASP, CDN and ad-network markets. It also explores the different business models for online video such as ad-supported (forecasts of ad revenues, ad types and total ad-supported video views), as well as pay markets (download to own, rental and subscription).

http://www.abiresearch.com/products/ market_research/Broadband_Video_and_ Internet_TV

Over-the-Top Internet Video to the TV: Analysis of Consumer Platform and Services Options

The market for premium internet content is expanding widely, as nearly all major studios and content aggregators work to ensure that some of their most prized content is available to consumers. ABI Research believes that bridging the divide between the internet and the television is one of the major challenges confronting this market. In this report, we evaluate the viability of the consumer platform/ service solutions available today. The number of different offerings include video game consoles, hybrid set-top boxes managed by video service providers and internet set-top boxes (such as Apple TV), and PVRs from vendors that are not service providers.

http://www.abiresearch.com/products/ research_brief/Digital_Media_Research_ Brief/107

Consumer Media: The Changing Ways in Which Consumers Buy, Consume and Manage Their Content

This report examines the media consumption habits of consumers. The study looks at how consumers use both traditional media television or music - and how this use is being increasingly balanced with enjoyment of media through new consumption and distribution methods. The main method of analyzing consumers' media consumption habits is through a survey conducted online in late April 2007 in North America. In addition to evaluating the survey results, we also apply some of the results to consumer technology needs such as storage, and forecast needs of consumers based on assumptions of future use.

\section{SOURCES AND METHODOLOGY}

Much of this white paper is based on a survey of approximately 1,192 online households in the United States completed in 2Q 2007. The survey covered a number of different age groups, as shown in Figure 1, and across a variety of different income groups, illustrated in Figure 2. For the forward-looking analysis, we applied our deep understanding of technology markets to the survey results and other important consumer market indicators to discuss trends around the future of consumer media consumption over the next five years. 